\title{
Design and Implementation of Closed Loop LCL-T Resonant DC-to- DC Converter Using Low Cost Embedded Controller
}

\author{
${ }^{1}$ M. Annamalai and ${ }^{2}$ M. Vijaya Kumar \\ ${ }^{1}$ Sathyabama University, Chennai, Tamil Nadu, India \\ ${ }^{2}$ Department of Electrical Engineering, JNTU, A.P, India
}

\begin{abstract}
The aim of this study is to simulate and implement open loop and closed loop controlled DC-DC converter for stand-alone wind energy system. Wind turbines, however, are not always very efficient in the wind speeds that are most common to a region. Typically, wind energy systems are designed to be highly efficient in high wind speed and have a cut-off wind speed- below which no energy is captured. In remote locations where wind energy is used for battery charging, the energy lost below the cut-off wind speed could be used for trickle charging or maintaining a battery's fully charged state. Wind turbines are most efficient when they are operated at one specific Tip-Speed to Wind-Speed Ratio (TSR). Therefore, for the efficient capture of wind power, turbine speed should be controlled to follow the ideal TSR, with an optimal operating point, which is different for every wind speed In this system, the DC-DC converter in the DC link with a constant dc voltage to the load, a DC-DC converter will allow the voltage at the output of a diode bridge rectifier to be controlled. In low wind speed conditions, the voltage may be lowered to prevent the dc link from reverse biasing the diode rectifier. Under high wind speed condition, the voltage may be increased, reducing I2R losses. In addition, adjusting the voltage on the dc rectifier will change the generator terminal voltage and thereby provide control over the current flowing out of the generator. The LCL-T resonant inverter system for both open loop and closed loop DC-to-DC converter systems are simulated using MATLAB simulink power system blocks. This converter has advantages like reduced transformer size, reduced filter size and current source characteristics. The simulation studies indicate that LCL-T type for open and closed loop DC-DC converter can be used with stand-alone wind generator. Constant voltage can be maintained at the output of DC-to-DC converter by using a PWM rectifier at the output. Embedded controlled DC to DC converter is fabricated and it is tested.
\end{abstract}

Keywords: Converter, Resonant Inverter, DC-DC Converter, MATLAB

\section{INTRODUCTION}

Small-scale stand-alone wind energy is increasingly viewed as a viable and sometimes preferred source of electrical energy. Consider, for example, remote villages in developing countries or ranches located far away from main power lines. Wind energy is a quiet alternative to remote diesel generation- that sometimes depends on excessive transportation and fuel storage costs-and an economically justifiable alternative to a grid connection. Corresponding Author: M. Annamalai, Sathyabama University, Chennai, Tamil Nadu, India

Wind energy is a quiet alternative to remote diesel generation-that sometimes depends on excessive transportation and fuel storage costs- and an economically justifiable alternative to a grid connection. It has been shown that a remote load has only to be a matter of a few miles away from a main power line for a stand-alone wind generator to be cost-effective (Kellogg et al., 1998).

A typical, small-scale, stand-alone, wind electric system is composed of a wind turbine, a permanent-magnet 
generator, a diode bridge rectifier and a dc power system. In many small-scale systems, the dc system is at a constant dc voltage and is usually comprised of a battery bank, allowing energy storage, a controller to keep the batteries from overcharging and a load. The load may be DC or may include an inverter to an AC system. The load configuration is beyond the scope of this study.

Unfortunately, there can be significant problems connecting a wind generator to a constant DC voltage. At low wind speeds, the induced voltage in the generator will not be high enough to overcome the reverse bias in the diode bridge. At high wind speed, the electrical frequency increases and the reactive impedance of the generator will be high, while the impedance of the battery load will be low. In this case, the poor impedance matching will limit power transfer to the DC system (Yamamura et al., 1999; Borage, 2005; Daniel and Gounden, 2004; Arutchelvi and Daniel, 2006; 2007).

Control of the DC-DC converter may be achieved by means of maximum power point tracking (Daniel and Gounden, 2004) or by means of a pre-determined relationship between wind speed and rectifier DC voltage (Arutchelvi and Daniel, 2006; 2007). Maximum power point tracking requires continuous variation of the DC voltage to determine whether the output power may be increased. This system is relatively complex. The relatively high turbine inertia can cause a significant time lag between the changes to the DC-link voltage and any observed change in power. Use of a predetermined relationship between wind speed and voltage may also have difficulties. Accurate wind speed measurement is difficult and requires the use of a relatively expensive anemometer if it is to be used for system control. The system proposed in this study makes use of a predetermined relationship between generator electrical frequency and DC-link voltage. Three ports triple half bridge bidirectional converters with zero voltage switching are given in (Tao and Hendix, 2008). Fuel cell and super capacitor are used as sources. Active snubber cell for DC to DC converter is given in (Hosseni and Moradi, 2008).

This study deals with a LCL-T resonant DC-DC converter that achieves constant wind turbine efficiency across a wide range of wind speeds. The system is designed for use in remote location and, therefore, includes a simple control strategy and a fault- tolerant topology. The control circuit included fault detection and has been tested with a parallel redundant DC link. Previously published works demonstrated the ability of the control system to detect both open- and short-circuit converter faults and switch to a parallel converter without interruption of the supply. The literature
(Kellogg et al., 1998) to (Hosseni and Moradi, 2008) does not deal with the simulation of closed loop controlled DC-to-DC converter. This study deals with closed loop controlled DC-to-DC converter. This study also compares the experimental results with the simulation results. The system represented in the Fig. 1 where VDC is a variable voltage and V BATT is a fixed DC voltage. System data are given in Table 1.

\subsection{Theoretical Approach}

The fundamental equation governing the power capture of a wind turbine is Equation 1:

$P_{t}=\frac{1}{2} \rho A C_{p} v_{w}^{3}$

where, Pt is turbine power, $\rho$ is air density, A is the swept turbine area, $\mathrm{Cp}$ is the turbine coefficient of performance and $v \omega$ is wind speed. The coefficient of performance is a function of TSR, described by Equation 2:

$\operatorname{TSR}=\frac{\mathrm{r} \omega_{\mathrm{m}}}{\mathrm{v}_{\oplus}}$

where, $\omega_{\mathrm{m}}$ is rotational speed, is the turbine radius and is wind speed. The maximum power captured by the wind turbine will occur when the TSR is approximately 7.5 , corresponding to a of 0.35 . A typical $\mathrm{Cp}$ curve shown in Fig. 2.

A relatively small deviation on either side of this TSR will result in a significant reduction of the power available for conversion to electrical energy. Employing control of the rotational speed of the turbine allows the TSR to be controlled and the coefficient of performance to be maximized. Thus, in turn, the generated electrical energy may be maximized. Control over the rotational speed is achieved by varying the generator terminal voltage.

A simple understanding of the ideal steady-state relationship between terminal voltage and rotational speed may be obtained by considering a generator with a fundamental current in phase with terminal voltage and neglecting harmonic currents.

Table 1. Wind energy system data

\begin{tabular}{ll}
\hline Effective turbine radius & $1.0 \mathrm{~m}$ \\
\hline Phase to phase winding inductance & $3.3 \mathrm{mh}$ \\
Phase to phase winding resistance & $0.51 \omega$ \\
Peak per phase torque constant & $0.71 \mathrm{~nm} / \mathrm{a}$ \\
Poles & 8 \\
System inertia & $1.2 \mathrm{~kg}-\mathrm{m}^{2}$ \\
System damping & $0.16 \mathrm{~nm} / \mathrm{krpm}$ \\
\hline
\end{tabular}




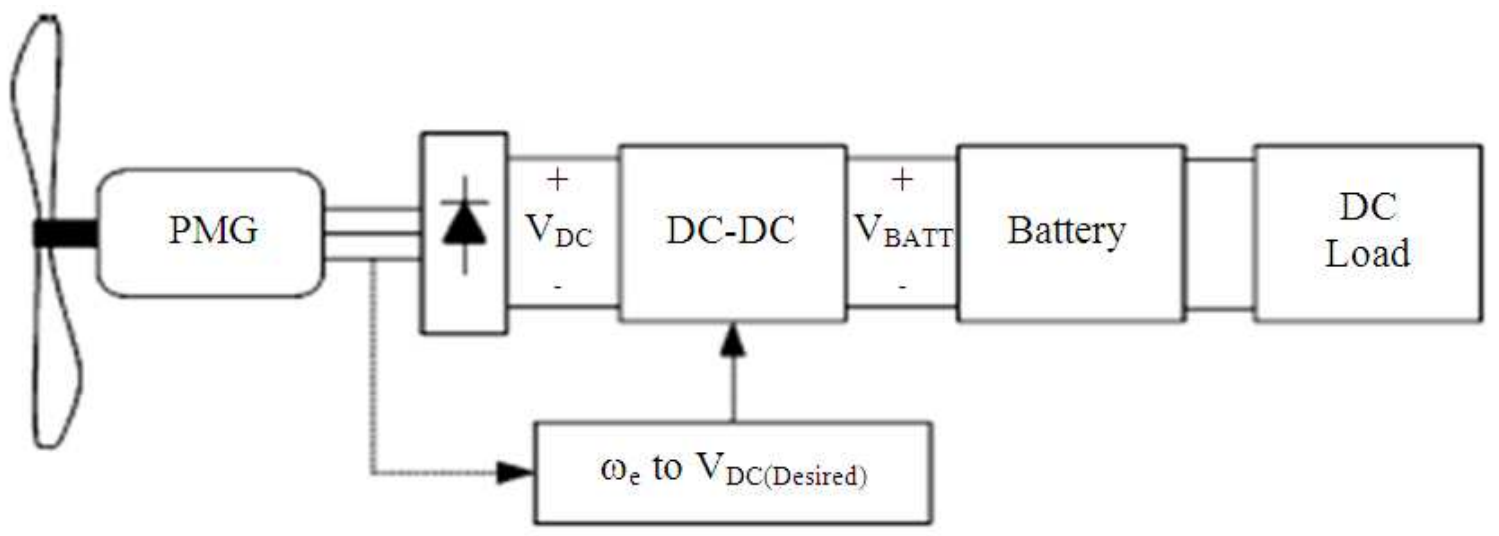

Fig. 1. Schematic diagram of the stand-alone wind Energy system under consideration

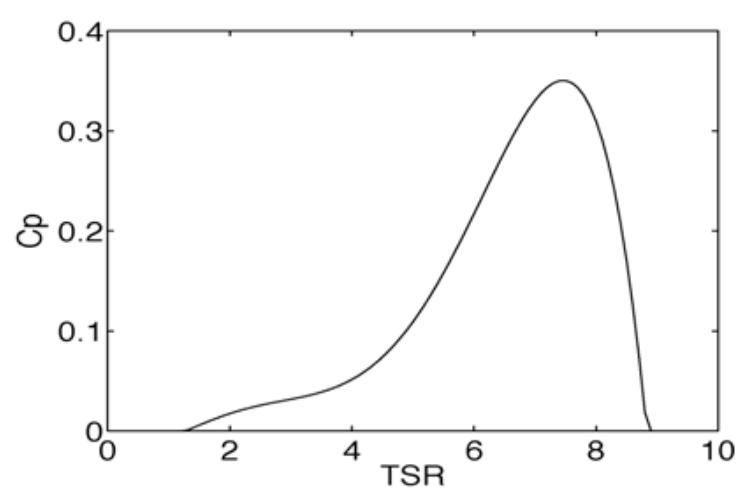

Fig. 2. Typical Cp curve

An approximation of the rectified dc-link voltage may be obtained using the standard equations for a threephase full-bridge diode rectifier with line inductance. It is possible to obtain a prediction for dc-link voltage as a function of mechanical speed (or electrical generated frequency) and TSR. In the ideal case, the generator operates at the peak of the curve.

\subsection{Design Calculations}

$48 \mathrm{~V} / 12 \mathrm{~V}$ transformer, fs $=20 \mathrm{KHz}, \mathrm{fr}=56 \mathrm{KHz}, \varphi$ $=10 \mu \mathrm{wb}, \mathrm{Lr}=9 \mu \mathrm{H}, \mathrm{RL}=100 \Omega, \mathrm{r}=7 \mathrm{e}-4$. The following assumptions are made:

(i) Saturation is neglected.

(ii) Magnetizing current is neglected Equation 3-5:

Using $\mathrm{E}_{1}=4.44 \times \mathrm{N}_{1} \times \varphi \times \mathrm{f}$

We obtain $\mathrm{N}_{1}=54$
Using $\mathrm{E}_{1}=4.44 \times \mathrm{N}_{1} \times \varphi \times \mathrm{f}$

We obtain $\mathrm{N}_{1}=13$

Using $f_{r}=1 / 2 \pi \sqrt{L_{r} C_{r}}$

We obtain $\mathrm{C}_{\mathrm{r}}=0.75 \mu \mathrm{F}$

Using $\mathrm{r}=1 / 4 \sqrt{3} \times \mathrm{f} \times \mathrm{C} \times \mathrm{R}_{\mathrm{L}}$

We obtain $\mathrm{C}=100 \mu \mathrm{F}$

The equation of inverter is as follows Equation 7-8:

$$
\begin{aligned}
& \mathrm{VO}=\mathrm{VD} \text { for } 0<\mathrm{t}<\mathrm{T} / 2 \\
& \mathrm{VO}=-\mathrm{VD} \text { for } \mathrm{T} / 2<\mathrm{t}<\mathrm{T}
\end{aligned}
$$

The ripple factor of the rectifier is Equation 9:

$\mathrm{r}=1 / 4 \sqrt{3} \mathrm{Fcr}$

\subsection{Simulation Results}

Simulation is done using MATLAB and the results are presented here. The DC-DC converter is shown in Fig. 3a. Scopes are connected to measure the driving pulses, DC output and current. The output of the inverter is stepped down and it is rectified using an uncontrolled rectifier. The transformer primary voltage is shown in Fig. 3b. The secondary voltage is shown in Fig. 3c. Transformer voltage is sinusoidal due to the presence of the T-filter. DC output voltage and current waveforms are shown in Fig. 3d. It can be seen that the output is free from ripple.

\subsection{Closed Loop System}

Open loop system with disturbance is shown in Fig. 4a. Disturbance source is represented as a subsystem. A step increase in input voltage is applied. 
M. Annamalai and M. Vijaya Kumar / American Journal of Engineering and Applied Sciences 5 (4) (2012) 291-300

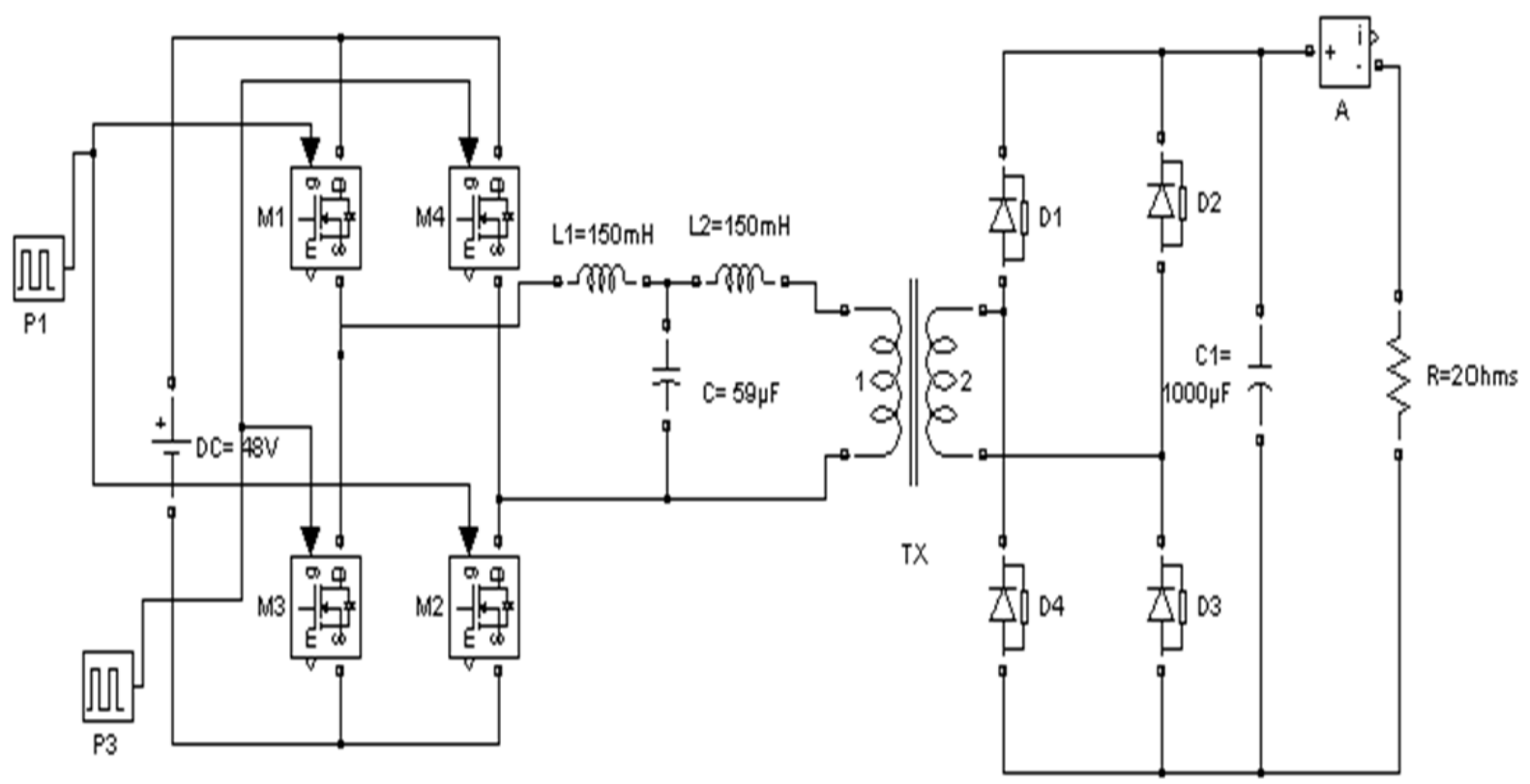

(a)

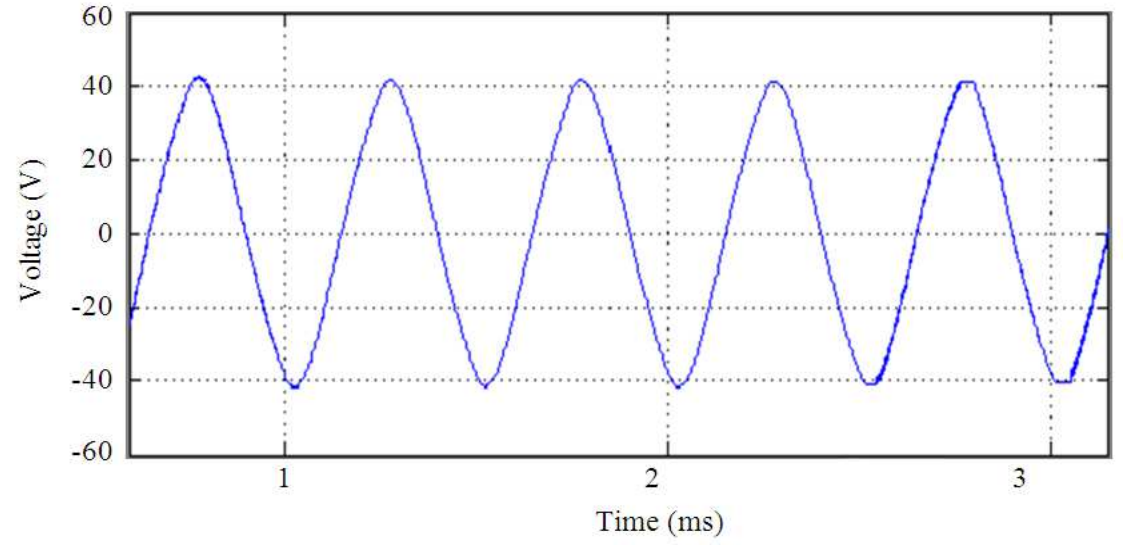

(b)

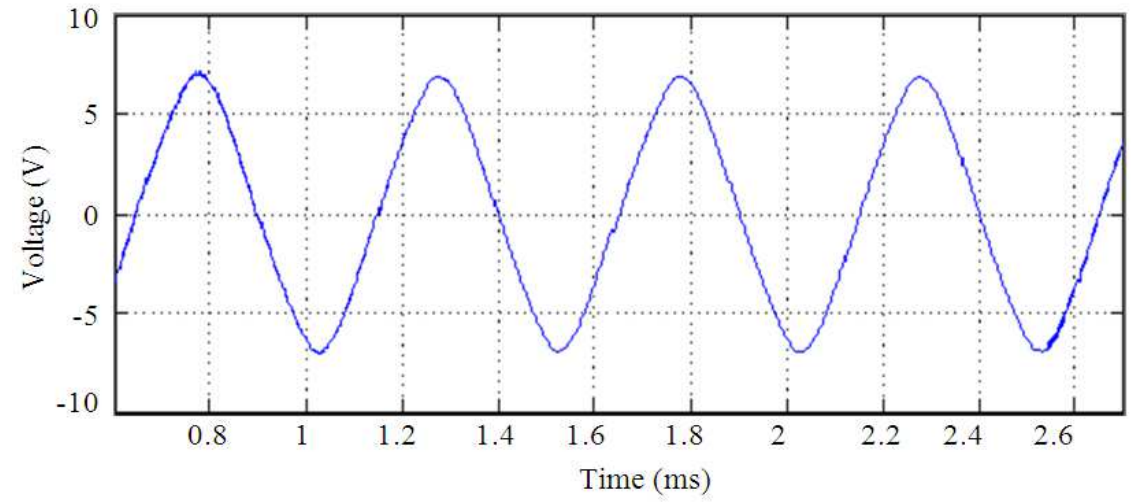

(c) 
M. Annamalai and M. Vijaya Kumar / American Journal of Engineering and Applied Sciences 5 (4) (2012) 291-300
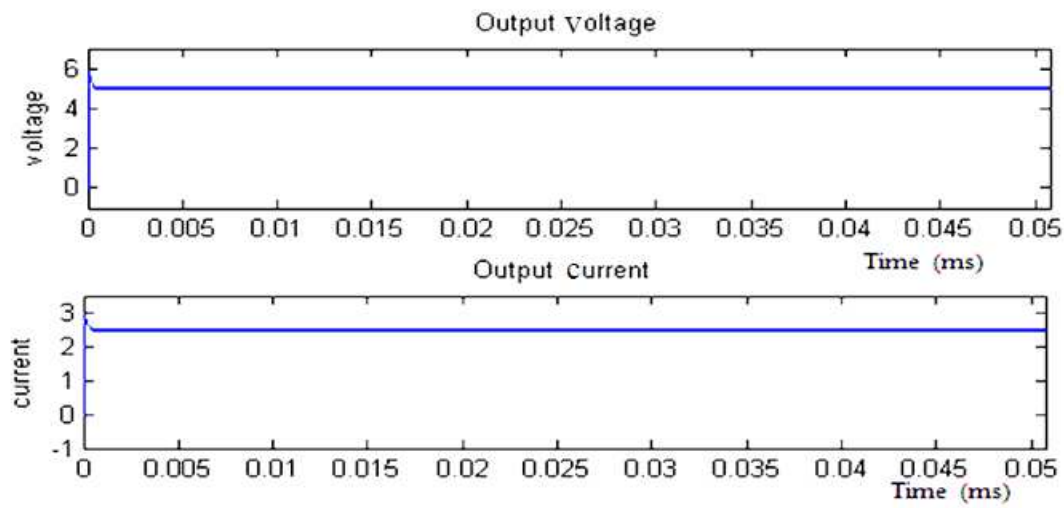

(d)

Fig. 3. (a). DC-DC converter circuit diagram, (b) Transformer primary voltage, (c) Transformer secondary voltage, (d) Voltage and current waveforms

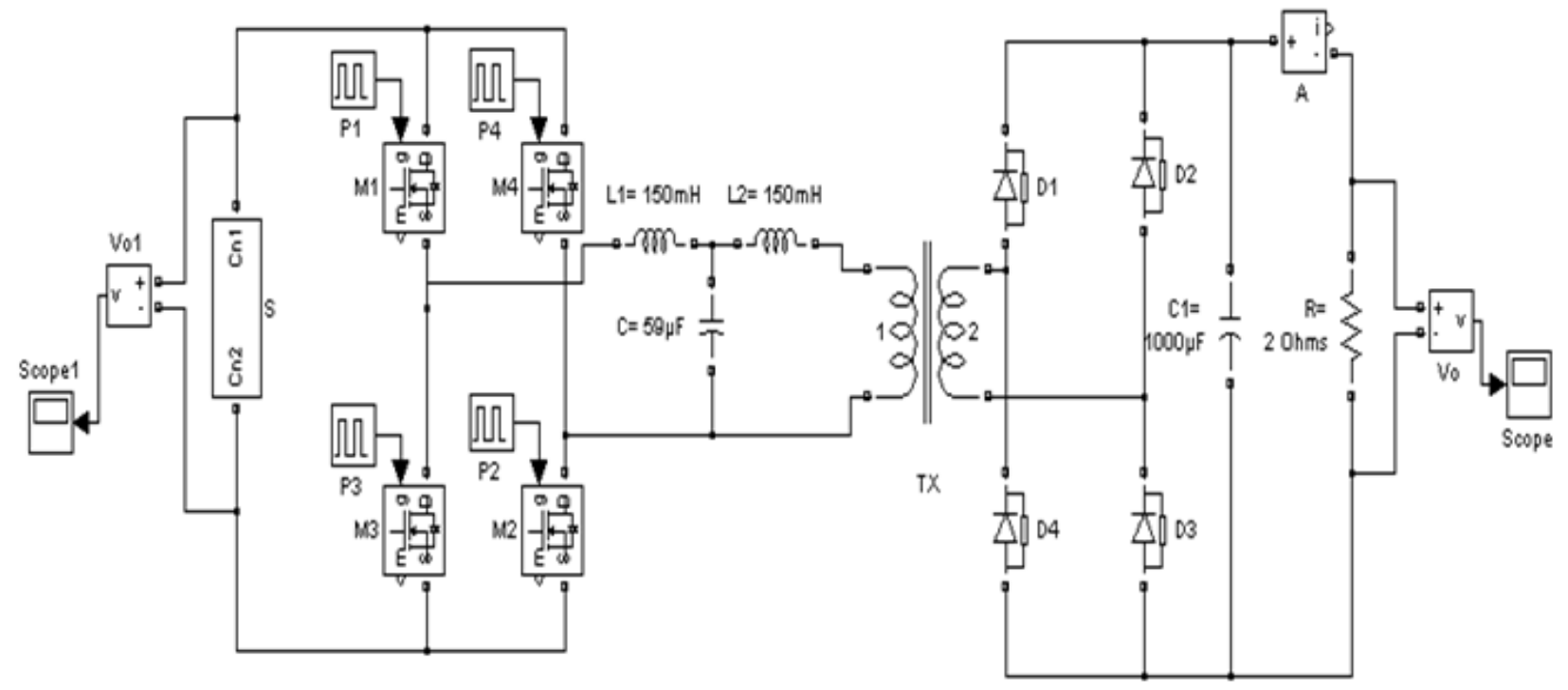

(a)

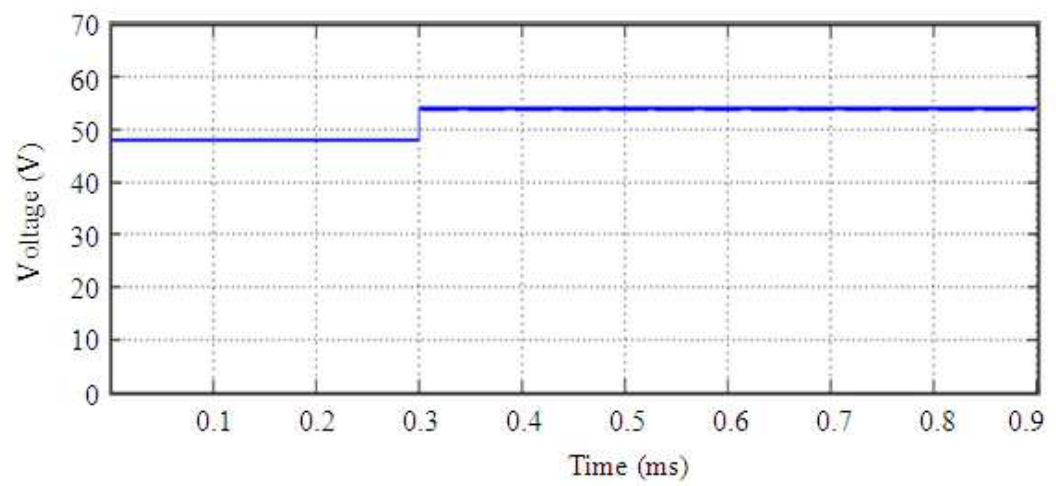

(b) 
M. Annamalai and M. Vijaya Kumar / American Journal of Engineering and Applied Sciences 5 (4) (2012) 291-300

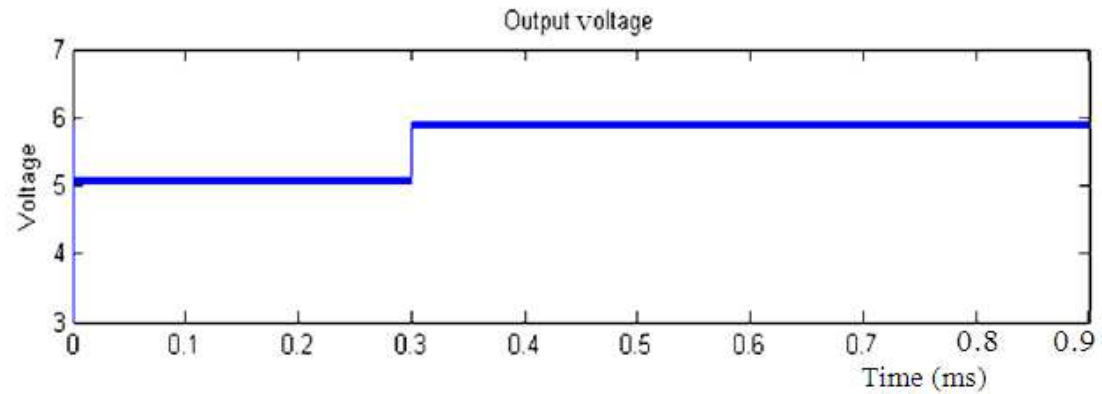

(c)

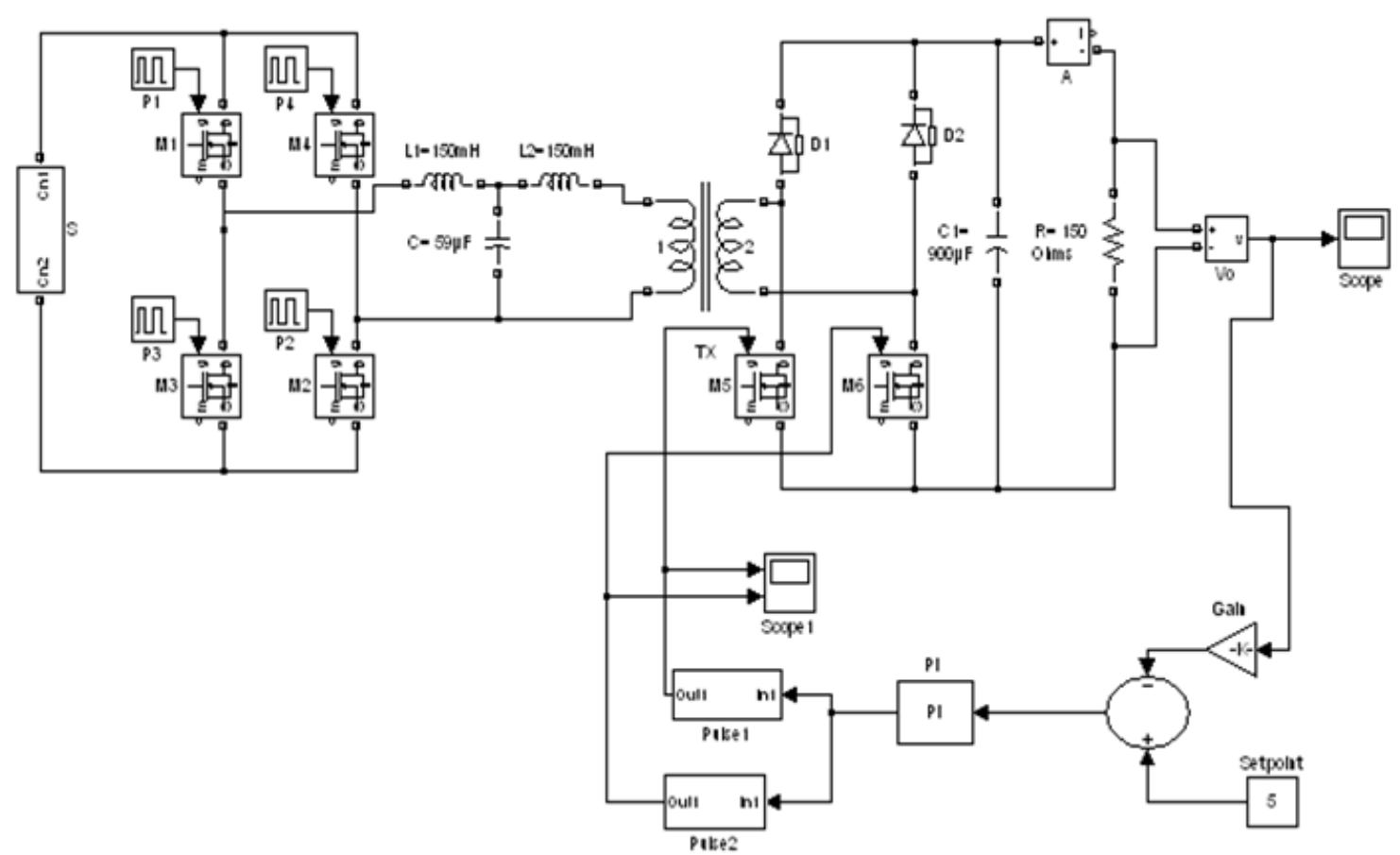

(d)

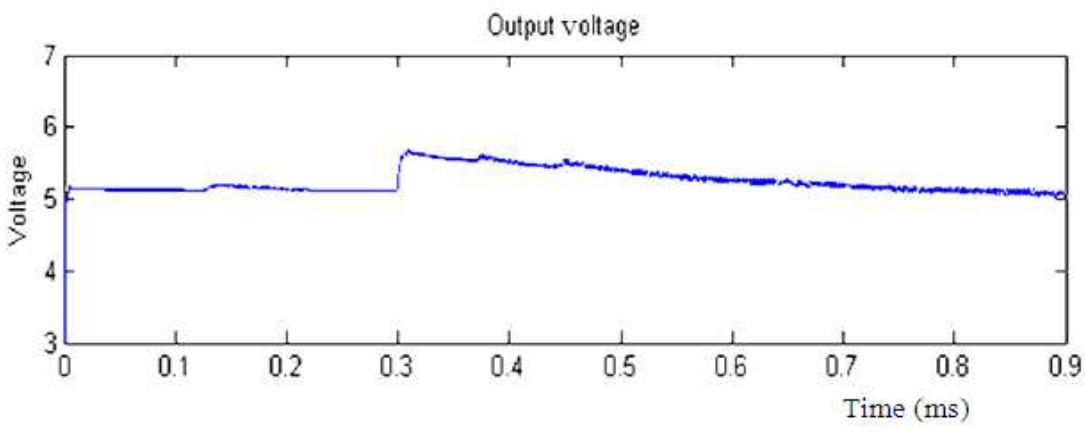

(e)

Fig. 4. (a) Open loop system with a disturbance (b) input voltage with disturbance (c) output voltage of open loop system (d) closed loop system (e) output voltage of closed loop system 
M. Annamalai and M. Vijaya Kumar / American Journal of Engineering and Applied Sciences 5 (4) (2012) 291-300

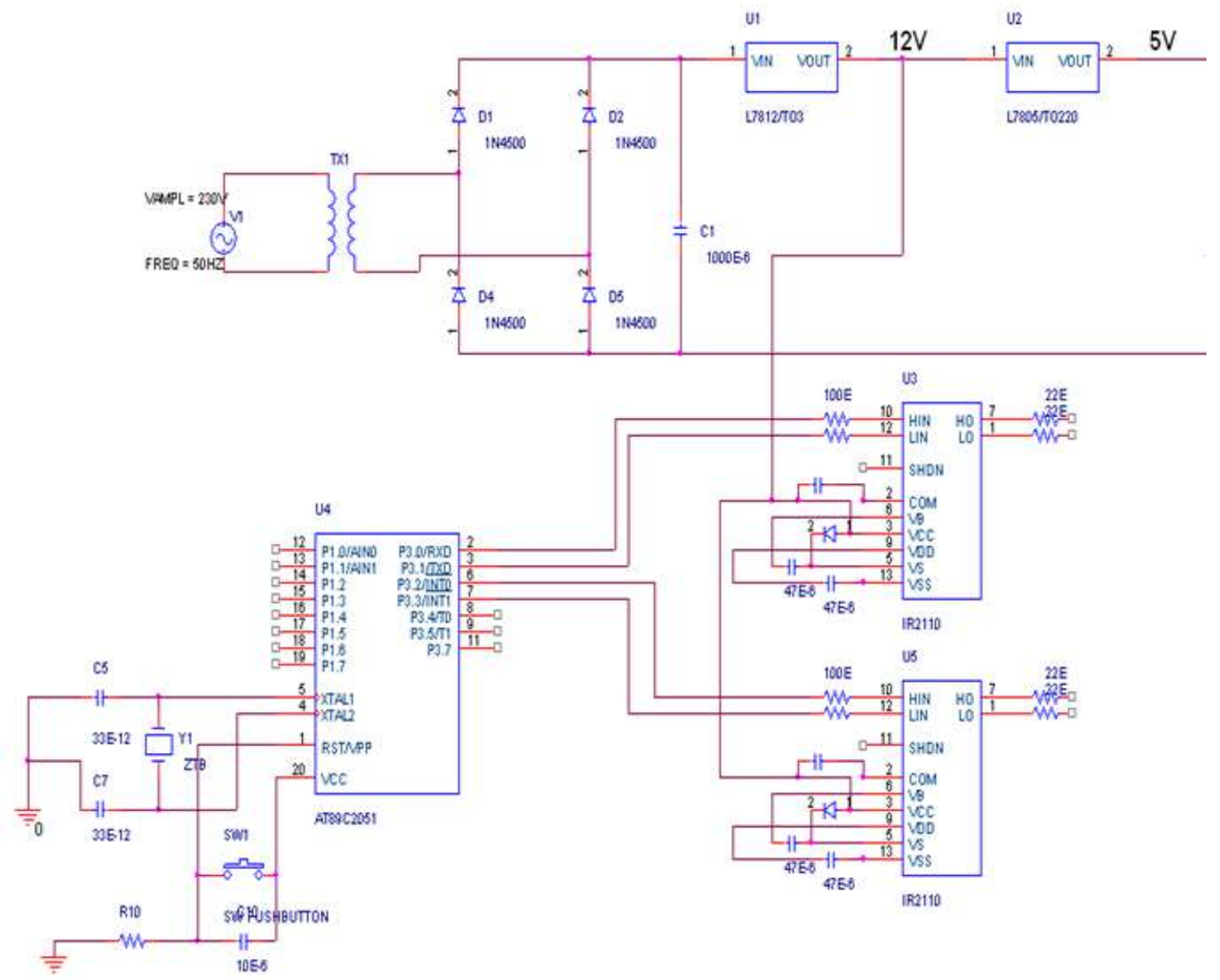

(a)

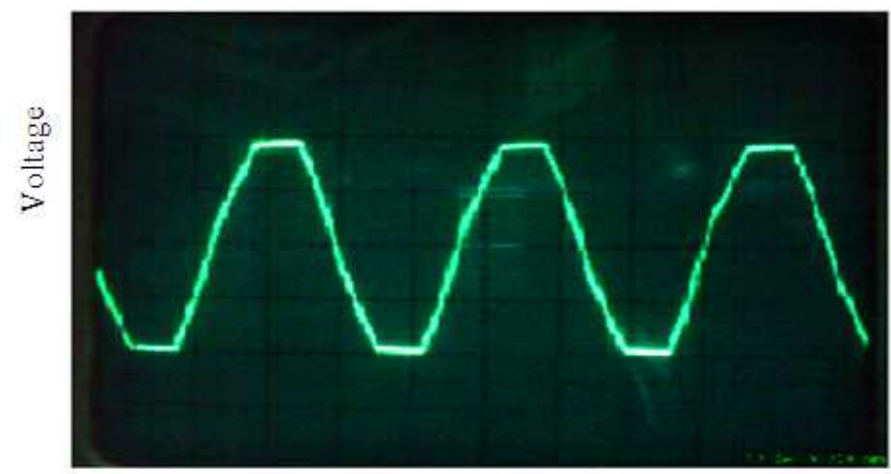

Time

$\mathrm{X}$ axis 1 unit $=2 \mathrm{~ms}$

$\mathrm{Y}$ axis 1 unit $=10 \mathrm{~V}$

(b) 
M. Annamalai and M. Vijaya Kumar / American Journal of Engineering and Applied Sciences 5 (4) (2012) 291-300

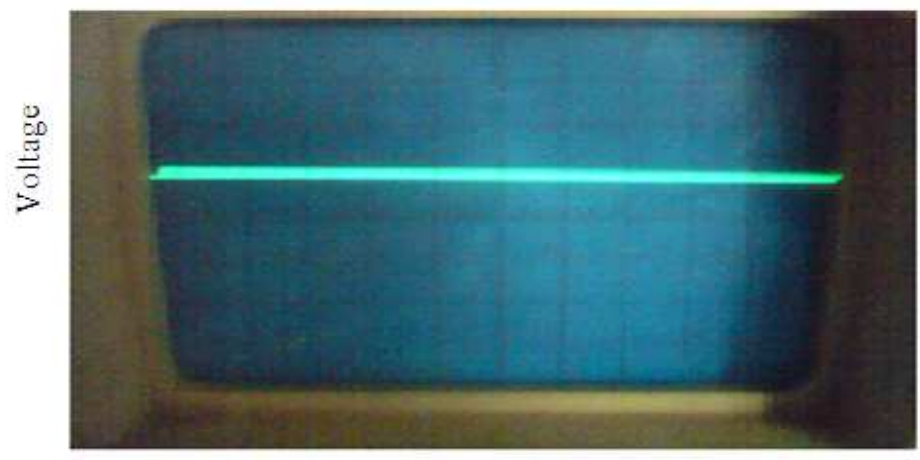

Time

$\mathrm{X}$ axis 1 unit $=2 \mathrm{~ms}$

$\mathrm{Y}$ axis $1 \mathrm{unit}=10 \mathrm{~V}$

(c)

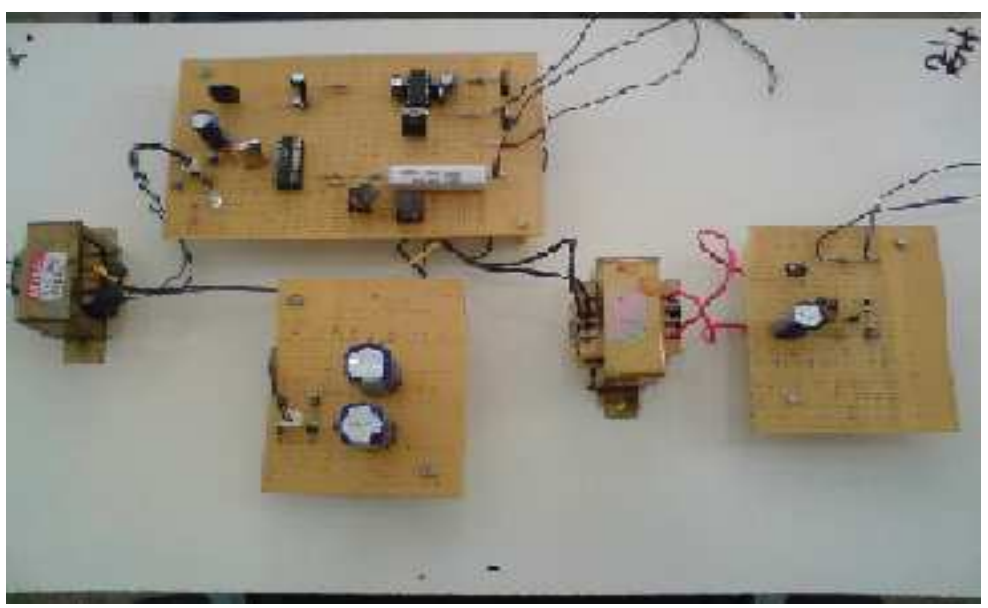

(d)

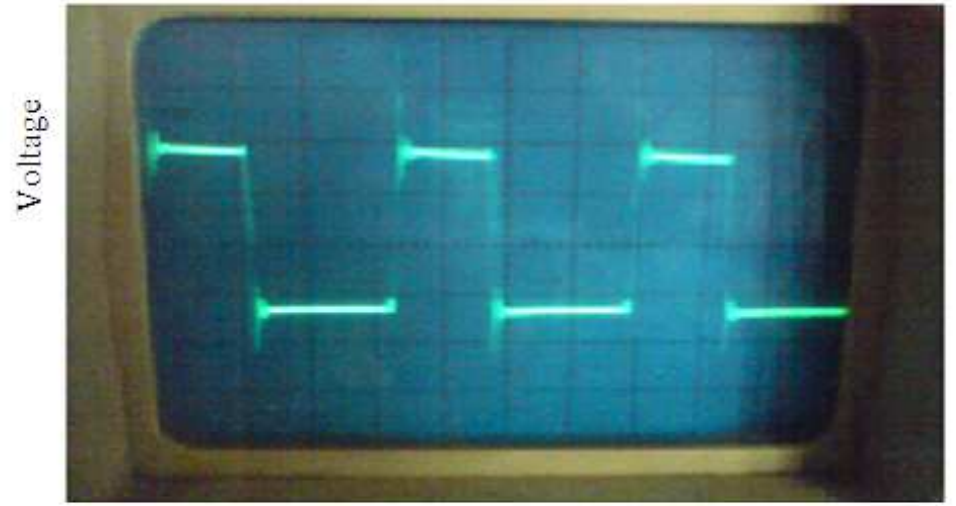

Time

$\mathrm{X}$ axis 1 unit $=2 \mathrm{~ms}$

$\mathrm{Y}$ axis $1 \mathrm{unit}=10 \mathrm{~V}$

(e)

298

AJEAS 


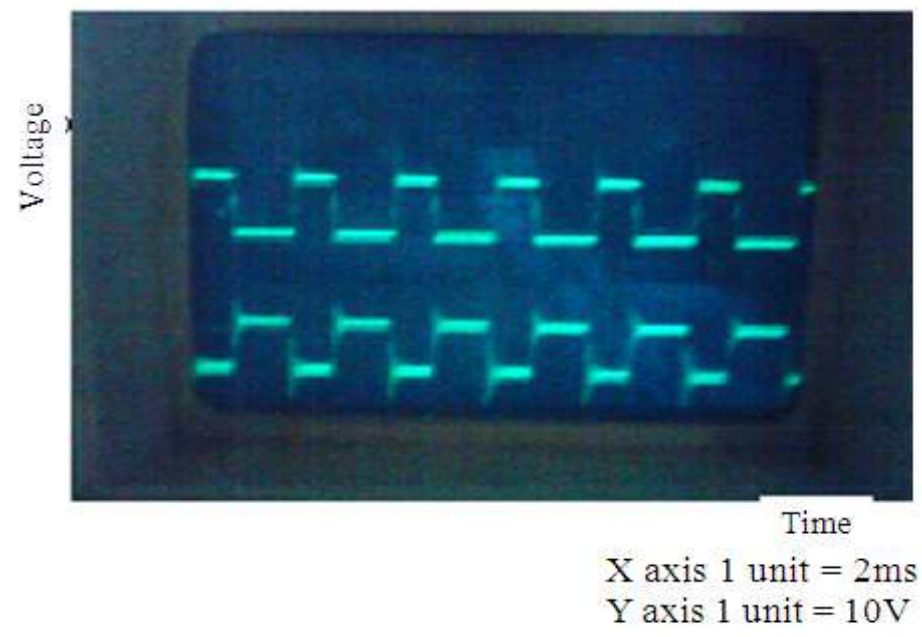

(f)

Fig. 5. (a) Control power circuit, (b) AC Input Voltage, (c) DC Output, (d) Top View of Hardware, (e) Primary Volta (f) Driving Pulses

The input voltage with disturbance is shown in Fig. 4b. The output voltage with disturbance is shown in Fig 4c. The output voltage also increases in open loop system. Closed loop system is shown in Fig. 4d. The output voltage is sensed and it is compared with a reference voltage of $5 \mathrm{~V}$. The error is given to a PI controller. The output of PI generates pulses with reduced width. When these pulses are applied to the MOSFET's in the output rectifier, the output reduces to the set value as shown in the Fig. 4e. Thus the closed loop system is capable of reducing the steady state error. The parameters of $\mathrm{KP}=4$ and $\mathrm{KI}=0.1$ are used for simulation studies.

\subsection{Hardware Implementation}

The hardware is implemented using a low cost embedded microcontroller Atmel 89C2051. The driving pulses required by the inverter are generated using embedded microcontroller. The pulses are amplified using a driver IC IR 2110. The control and power circuits are fabricated and tested shown in Fig. 5a. AC input voltage is shown in Fig. 5b. DC output is shown in Fig. 5c. Top view of the hardware is shown in Fig. 5d. The hardware consists of driver board and power board. Voltage across the primary is shown in Fig. 5e. Driving pulses are shown in Fig. 5f. From the Fig. 4 and 5, it can be seen that the experimental results coincide with the simulation results.

\section{CONCLUSION}

The open loop and closed loop controlled DC-DC converter systems are simulated using MATLAB version
7.1 and the results are presented. This converter is popular due to reduced EMI, reduced stresses and high power density. The simulation studies indicate that LCL type DC-DC converter can be used with stand-alone wind generator. Constant voltage can be maintained at the output of DC-to-DC converter by using a PWM rectifier at the output. Simulation results indicate the validity of closed loop model. Embedded controlled DC to DC converter is fabricated and it is tested. The experimental results closely agree with the simulation results.

The closed loop system is implemented using PI controller. The closed loop system may be attempted with a better intelligent controller.

\section{REFERENCES}

Arutchelvi, M. and S.A. Daniel, 2006. Voltage control of an autonomous hybrid generation scheme based on PV array and wind-driven induction generators. Induct. Elect. Power Components Syst., 34: 759773. DOI: $10.1080 / 15325000500488594$

Arutchelvi, M. and S.A. Daniel, 2007. Composite controller for a hybrid power plant based on PV array fed wind-driven induction generator with battery storage. Int. J. Energy Res., 31: 515-524. DOI: DOI: 10.1002/er.1262

Borage, M., 2005. Analysis and design of an LCL-T resonant converter as a constant-current power supply. IEEE Trans. Indus. Elect., 52: 1547-1554. DOI: 10.1109/TIE.2005.858729 
Daniel, S.A. and N.A. Gounden, 2004. A novel hybrid isolated generating system based on PV fed inverterassisted wind-driven induction generators. IEEE Trans. Energy Conv., 19: 416-422. DOI: 10.1109/TEC.2004.827031

Hosseni, S.H. and R. Moradi, 2008. A new active snubber cell for DC to DC converter. IEEE Trans. Power Elect.

Kellogg, W.D., M.H. Nehrir, G. Venkataramanan and V. Gerez, 1998. Generation unit sizing and cost analysis for stand-alone wind, photovoltaic and hybrid wind/PV systems. IEEE Trans. Energy Conv., 13: 70-75. DOI: 10.1109/60.658206
Tao, H. and A.M. Hendix, 2008. Three-port triple-halfbridge bidirectional converter with zero-voltage switching. IEEE Trans. Power Elect., 23: 782-792. DOI: 10.1109/TPEL.2007.915023

Yamamura, N., M. Ishida and T. Hori, 1999. A simple Wind power generating system with permanent Magnet type synchronous generator. Proceedings of the IEEE International Conference Power Electronics Drive Systems, Jul. 27-29, IEEE Xplore Press, pp: 849-854. DOI: 10.1109/PEDS. 1999.792817 